\title{
The role of tropospheric ozone in flagging COVID-19 pandemic transmission
}

\author{
S. Lolli $^{1}$ (D) $\cdot$ G. Vivone ${ }^{1}$
}

Received: 2 October 2020 / Accepted: 30 November 2020/ Published online: 15 December 2020

(C) The Author(s), under exclusive licence to Springer Nature Switzerland AG part of Springer Nature 2020

\begin{abstract}
COVID-19 pandemic outbreak, caused by the SARS-CoV-2 virus, affected millions of people worldwide causing hundreds of thousands of related fatalities. It is crucial to understand why the virus transmission seems to spread more easily in some regions than others. The residuals, with respect to the modeled COVID-19 per-day hospitalized patients in intensive care unit, are correlated to the meteorological and air-pollutant variables in four major metropolitan areas in Italy during a strict lockdown implemented by the Italian government, making the analysis independent from socio-economic factors. The results show that COVID-19 pandemic-related infections are slowed down by higher tropospheric ozone concentrations and eased by the atmospheric particulate. We quantitatively assessed that higher levels of tropospheric ozone, already proven effective against viruses and microbial contaminants, play a role in flagging COVID-19 pandemic transmission. Because the tropospheric ozone production is depending, among others, by airquality and sunlight, this can explain why the virus is spreading in different ways.
\end{abstract}

Keywords COVID-19 $\cdot$ Tropospheric ozone $\cdot$ Air quality $\cdot$ Infectious diseases

In March 2020, the World Health Organization declared pandemic the new Sars-CoV-2 virus outbreak that infected millions of people worldwide, with consequent hundreds of thousands of fatalities. Understanding why the SARS CoV-2 is selectively spreading, i.e., to understand why the virus strongly hits some parts of the world with a subsequent large number in terms of infected people and fatalities, while others regions are spared with much lesser infected and fatalities, is of fundamental importance to implement strategies at government level to contrast and contain any possible outbreak. Recent studies (Liu et al. 2020; Lolli et al. 2020) have already highlighted how the meteorological variables, e.g., temperature and humidity, can affect COVID-19 pandemic transmission. In this study, we assessed how the atmospheric particulate and the ozone tropospheric concentration affect COVID-19 pandemic transmission

\section{S. Lolli}

simone.lolli@imaa.cnr.it 
in four major metropolitan areas in Italy. We collected the main meteorological and airpollution-related variables from 1 February 2020 to 31 May 2020 in Milan, Trento, Florence, and Rome. We tested the non-linear Kendall and Spearman correlations between those parameters and the residual number of the hospitalized patients in the intensive care unit (ICU) as shown in Lolli et al. (2020). The number of hospitalized patients in ICU unit is a much stronger indicator of COVID-19 pandemic transmission because it is independent of the number nasopharyngeal swabs performed. In agreement with Lolli et al. (2020), we consider a delay of 19 days between the infection and the development of the acute respiratory distress syndrome (ARDS) that requires patient hospitalization into the ICU unit in critical conditions. For this reason, both the meteorological and air-pollution data are 19 days back time-shifted, as shown in Lolli et al. (2020). This means that the daily number of ICU patients from 24 February 2020 to 14 June 2020 is based on infections that happened from 5 February 2020 to 26 May 2020. The ICU per-day cases are modeled following the Gaussian mixture model (GMM) that seems to better represent the COVID-19 behavior in terms of infections and ICU hospitalizations as reported in Singhal et al. (2020). In this study, we adopted the Bi-Gaussian model. This choice is corroborated by some tests performed that put in evidence the inadequacy of a simple Gaussian in modeling the epidemiologic trend, while Gaussians with more than three terms are overfitting the data canceling all the valuable information. The ICU hospitalized number of patients show different trends with respect to time, i.e., in the early phase, the ICU patient number grows exponentially up to a plateau and it is followed by an exponential drop in the late phase. The curve symmetry is strictly dependent, among other variables, on lockdown policies implemented at government level. For this reason, the correlation analysis would give very different results if applied on a different temporal period, i.e., the results from Spearman and Kendall rank tests during the growing phase will be completely different with respect to the drop phase. To make the analysis independent on those issues, we consider instead the per-day residual number of ICU patients with respect to the GMM model, extrapolated from the data trend. The model should account for the natural tendency of the viral epidemic and the effect of the lock-down on it. Thus, the residual analysis (i.e., the differences between the GMM model and the observed cases) should preserve from spurious correlations between the above-mentioned effects and the parameters under analysis. Indeed, the considered atmospheric parameters quickly change (sometimes day-to-day), representing a divergence factor (residue) with respect to the model and characterizing the existing anomaly about the classical behavior described by the model.

\section{Results}

In Fig. 1, we show the model, and the per-day number of ICU hospitalized patients for Milan, Trento, Florence, and Rome and the corresponding residuals.

The correlations between COVID-19 pandemic and meteorological and air pollution variables were investigated using non-linear Spearman and Kendall rank correlation tests. The Spearman rank correlation non-parametric test $r_{s}$ is (Lolli et al. 2020):

$$
r_{s}=1-\frac{6 \times \sum_{i} d_{i}^{2}}{n\left(n^{2}-1\right)},
$$

where $d_{i}$ is the difference between the ranks of two parameters, and $n$ the number of alternatives. Equation (2) shows the Kendall rank correlation non-parametric test $\tau$. 

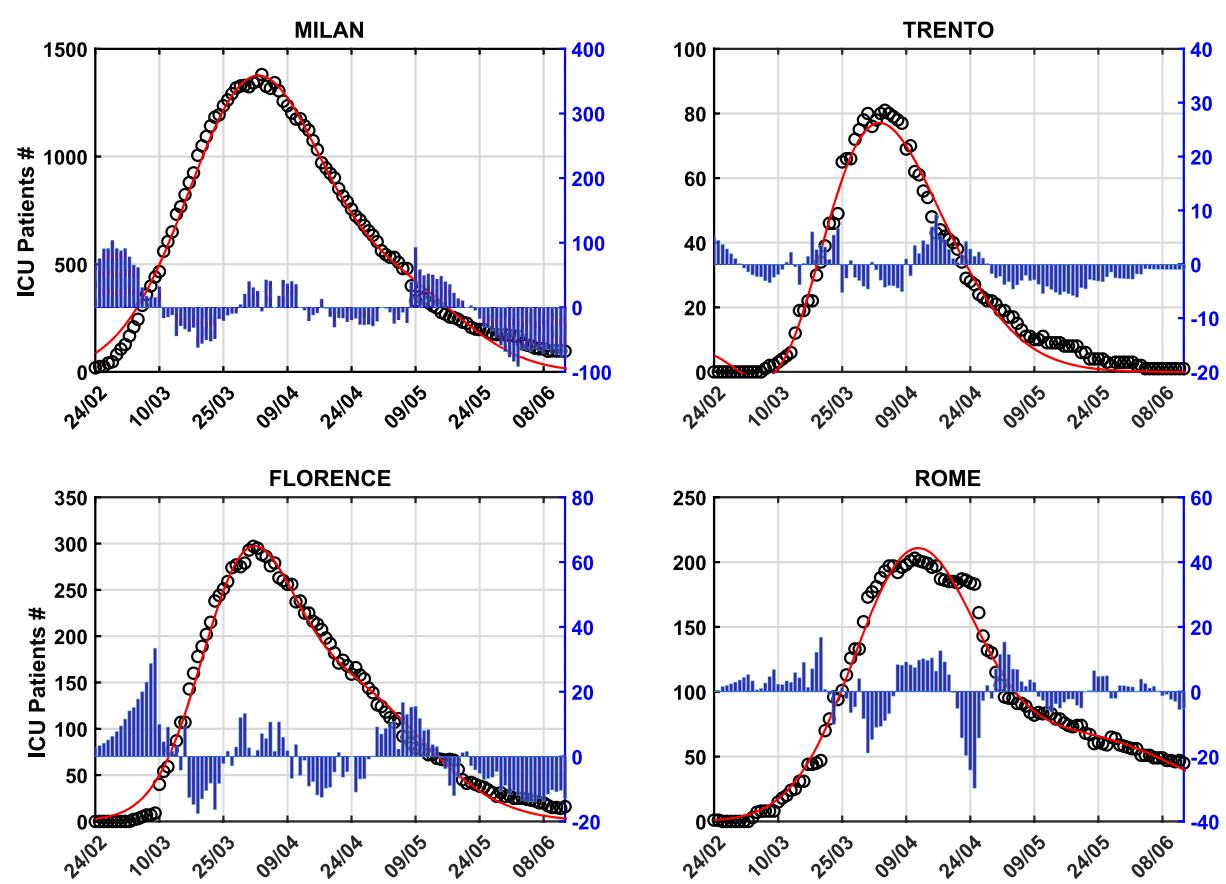

Fig. 1 ICU-admitted patients fitted by a Bi-Gaussian function (red line) extrapolated from the observed data (black circle dots). We use the residuals to investigate the correlation with the meteorological and air-pollution variables. In blue, we show the residuals (GMM-ICU patients)

$$
\tau=\frac{\text { concor-discor }}{0.5 \times n \times(n-1)},
$$

where concor represents the number of concordant pairs, while discor represents the discordant pairs, and $n$ is the number of pairs. Values of $r_{s}$ and $\tau$ equal to +1 and -1 imply a perfect positive and negative correlation, respectively. We analyzed the non-linear correlation between the daily max temperature $\left(T_{\max }\right)$, the daily average temperature $\left(T_{\mathrm{avg}}\right)$, and the minimum daily temperature $\left(T_{\min }\right)$. For humidity, the correlation was tested for the maximum, average and minimum dew point (DP) temperature, denoted as $\mathrm{DP}_{\max }, \mathrm{DP}_{\mathrm{avg}}$, and $\mathrm{DP}_{\min }$, respectively. Moreover, the water vapor (WV in $\mathrm{g} \mathrm{kg}^{-1}$ ) concentration and the absolute humidity $(\mathrm{AH})$ in $\mathrm{g} \mathrm{m}^{-3}$ ) through the Clausius-Clapeyron equation (Qi et al. 2020) are considered. These can be described through the following equations:

$$
\begin{gathered}
\boldsymbol{W} \boldsymbol{V}=\mathbf{6 . 2 2} \times \boldsymbol{R} \boldsymbol{H} \times \frac{\mathbf{6 . 1 1 2} \times \mathbf{e x p}\left(\frac{\mathbf{1 7 . 6 7} \times \boldsymbol{T}}{\mathbf{2 4 3 . 5}+\boldsymbol{T}}\right)}{\boldsymbol{P}}, \\
A H=2.1674 \times R H \times \frac{6.112 \times \exp \left(\frac{17.67 \times T}{243.5+T}\right)}{273.15+T},
\end{gathered}
$$

where RH is the daily averaged relative humidity, $T$ is the daily averaged temperature, and $P$ is the daily averaged atmospheric pressure. As for the air-pollution parameters, we tested the 
correlations for the fine particulate matter $\left(\mathrm{PM}_{2.5}\right)$ and the ozone $\left(\mathrm{O}_{3}\right)$ concentrations. The meteorological data are publicly available on https://wunderground.com, while the airpollution data, i.e., $\mathrm{PM}_{2.5}$ and $\mathrm{O}_{3}$ daily averaged concentrations, are freely available (or on request for Milan and Lombardy region) from the regional environmental protection agency websites.

The results, reported in Table 1, put in evidence that the ozone concentration, the temperature, and the humidity (except for Florence) strongly negatively correlates with COVID-19 pandemic transmission for the analyzed metropolitan areas. For the $\mathrm{PM}_{2.5}$ concentrations instead, a positive correlation is found for all the analyzed areas. Table 2 shows correlation significance through the $p$ value. In other words, the correlations are gauged against some "null" hypothesis, i.e., by computing the probability that a totally uncorrelated dynamics would generate ranks that have a Spearman and Kendall correlation at least as high as the one computed from the actual residuals. In this work, we assume the correlation significant when the $p$ value is less than 0.01 .

\section{Discussion}

To the best of our knowledge, no previous studies demonstrated a strong and clear negative correlation between ozone concentration and COVID-19 pandemic transmission. On the contrary, positive correlations with the atmospheric particulate were already assessed (Di Girolamo 2020). This result can be assumed as a secondary factor to explain the differential virus transmission in the different parts of the world. Dubuis et al. (2020) corroborates this speculation, as their findings suggest that low concentration ozone is a powerful disinfectant for airborne viruses as well as the higher humidity of the air. Of course, in their work, the ozone concentrations are much higher, but in the atmosphere the ozone concentration lasts for much more time. Moreover, $\mathrm{O}_{3}$ production in the troposphere is strongly linked to sunlight and pollutants, i.e., precursors as $\mathrm{NO}_{2}$. Conversely, the presence of black carbon in the polluted metropolitan areas inhibits the

Table 1 Analysis on meteorological and air pollution parameters. Temperature and ozone correlate significantly with ICU residual patient number for the metropolitan areas; $n s$, a correlation not statistically significative

\begin{tabular}{|c|c|c|c|c|c|c|c|c|}
\hline & \multicolumn{4}{|l|}{ Kendall } & \multicolumn{4}{|c|}{ Spearman } \\
\hline & Milan & Trento & Florence & Rome & Milan & Trento & Florence & Rome \\
\hline $\mathrm{T}_{\max }$ & -0.21 & -0.23 & -0.29 & -0.21 & -0.3 & -0.37 & -0.4 & -0.42 \\
\hline $\mathrm{T}_{\mathrm{avg}}$ & -0.19 & -0.28 & -0.28 & -0.17 & -0.31 & -0.45 & -0.4 & -0.39 \\
\hline $\mathrm{T}_{\min }$ & -0.19 & -0.34 & -0.24 & -0.12 & -0.27 & -0.52 & -0.34 & -0.31 \\
\hline $\mathrm{DP}_{\max }$ & -0.19 & -0.41 & $\mathrm{~ns}$ & -0.13 & -0.27 & -0.61 & ns & -0.19 \\
\hline $\mathrm{DP}_{\mathrm{avg}}$ & -0.21 & -0.38 & ns & -0.13 & -0.31 & -0.56 & ns & -0.2 \\
\hline $\mathrm{DP}_{\min }$ & -0.22 & -0.33 & $\mathrm{~ns}$ & -0.15 & -0.32 & -0.51 & ns & -0.19 \\
\hline $\mathrm{AH}$ & -0.25 & -0.42 & ns & ns & -0.37 & -0.61 & ns & $\mathrm{ns}$ \\
\hline WV & -0.23 & -0.41 & ns & ns & -0.33 & -0.62 & ns & ns \\
\hline $\mathrm{PM}_{2.5}$ & 0.21 & 0.19 & 0.23 & 0.30 & 0.27 & 0.33 & 0.37 & 0.41 \\
\hline $\mathrm{O}_{3}$ & -0.22 & -0.24 & -0.2 & -0.37 & -0.40 & -0.39 & -0.31 & -0.54 \\
\hline
\end{tabular}


Table 2 Statistical significance of the correlation analysis. The correlation is gauged against some "null" hypothesis. We considered the correlations statistically significant when the $p$ value is less than 0.01 . In italics are the non-significant

\begin{tabular}{|c|c|c|c|c|c|c|c|c|}
\hline & \multicolumn{4}{|l|}{ Kendall } & \multicolumn{4}{|c|}{ Spearman } \\
\hline & Milan & Trento & Florence & Rome & Milan & Trento & Florence & Rome \\
\hline $\mathrm{T}_{\max }$ & $<0.01$ & $<0.01$ & $<0.01$ & -0.21 & $<0.01$ & $<0.01$ & $<0.01$ & $<0.01$ \\
\hline $\mathrm{T}_{\text {avg }}$ & $<0.01$ & $<0.01$ & $<0.01$ & -0.17 & $<0.01$ & $<0.01$ & $<0.01$ & $<0.01$ \\
\hline $\mathrm{T}_{\min }$ & $<0.01$ & $<0.01$ & $<0.01$ & -0.12 & $<0.01$ & $<0.01$ & $<0.01$ & $<0.01$ \\
\hline $\mathrm{DP}_{\max }$ & $<0.01$ & $<0.01$ & 0.038 & -0.13 & $<0.01$ & $<0.01$ & 0.033 & $<0.01$ \\
\hline $\mathrm{DP}_{\mathrm{avg}}$ & $<0.01$ & $<0.01$ & 0.029 & -0.13 & $<0.01$ & $<0.01$ & 0.031 & $<0.01$ \\
\hline $\mathrm{DP}_{\min }$ & $<0.01$ & $<0.01$ & 0.056 & -0.15 & $<0.01$ & $<0.01$ & 0.049 & $<0.01$ \\
\hline $\mathrm{AH}$ & $<0.01$ & $<0.01$ & 0.043 & 0.016 & $<0.01$ & $<0.01$ & 0.041 & 0.019 \\
\hline WV & $<0.01$ & $<0.01$ & 0.041 & 0.014 & $<0.01$ & $<0.01$ & 0.031 & 0.018 \\
\hline $\mathrm{PM}_{2.5}$ & $<0.01$ & $<0.01$ & $<0.01$ & $<0.01$ & $<0.01$ & $<0.01$ & $<0.01$ & $<0.01$ \\
\hline $\mathrm{O}_{3}$ & $<0.01$ & $<0.01$ & $<0.01$ & $<0.01$ & $<0.01$ & $<0.01$ & $<0.01$ & $<0.01$ \\
\hline
\end{tabular}

ozone production in the boundary layer ( $\mathrm{Li}$ et al. 2005). All those factors could partially explain the differential transmission. The results highlight that the ozone concentration should be considered as a co-factor in COVID-19 pandemic transmission, while the epidemiologic aspects are of paramount importance and have obviously the primary role.

Acknowledgments The authors equally acknowledge Wunderground for the meteorological data; Arpa Toscana, Arpa Lombardia, Arpa Lazio, and the Autonomous Province of Trento for $\mathrm{PM}_{2.5}$ and $\mathrm{O}_{3}$ concentrations; and the Italian Civil protection for the ICU-hospitalized patients.

\section{Compliance with ethical standards}

Conflict of interest The authors declare that they have no conflict of interest.

\section{References}

Di Girolamo P (2020) Assessment of the potential role of atmospheric particulate pollution and airborne transmission in intensifying the first wave pandemic spread of SARS-CoV-2/COVID-19 in Northern Italy. Bull Atmos Sci Technol. https://doi.org/10.1007/s42865-020-00024-3

Dubuis ME, Dumont-Leblond N, Laliberté C et al (2020) Ozone efficacy for the control of airborne viruses: Bacteriophage and norovirus models. PLoS One 15(4):e0231164. Published 2020 Apr 10. https://doi.org/10. 1371/journal.pone.0231164

Li G, Zhang R, Fan J, Tie X (2005) Impacts of black carbon aerosol on photolysis and ozone. J Geophys Res 110:D23206. https://doi.org/10.1029/2005JD005898

Liu Y, Ning Z, Chen Y, Guo M, Liu Y, Gali NK, Sun L, Duan Y, Cai J, Westerdahl D, Liu X, Xu K, Ho K, Kan H, Fu Q, Lan K (2020) Aerodynamic analysis of SARS-CoV-2 in two Wuhan hospitals. Nature. 582:557560. https://doi.org/10.1038/s41586-020-2271-3

Lolli S, Chen Y, Wang S, Vivone G (2020) Impact of meteorological conditions and air pollution on COVID-19 pandemic transmission in Italy. Sci Rep 10(16213):16213. https://doi.org/10.1038/s41598-020-73197-8

Qi H, Xiao S, Shi R, Ward MP, Chen Y, Tu W, Su Q, Wang W, Wang X, Zhang Z (2020) COVID-19 transmission in mainland China is associated with temperature and humidity: a time-series analysis. Sci Total Environ 728:138778. https://doi.org/10.1016/j.scitotenv.2020.138778

Singhal A, Singh P, Lall B, Joshi SD (2020) Modeling and prediction of COVID-19 pandemic using Gaussian mixture model. Chaos, Solitons Fractals 138:110023. https://doi.org/10.1016/j.chaos.2020.110023 